\title{
Sorption of water-ethanol mixtures by poplar wood: swelling and viscoelastic behaviour
}

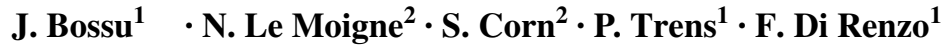

\begin{abstract}
The swelling of wood upon impregnation by aqueous solutions of organic solvents is larger than swelling by pure water. This phenomenon, described as "hyperswelling", results from specific interactions with components of the complex wood microstructure. To understand the combined effect of mixed solvents on wood properties, the specific influence of each solvent on wo od biopolymers and structure must be first characterized. In this study, the effect of the impregnation of aqueous solutions of ethanol with concentrations from 0 to $100 \%$ on the physico-mechanical properties of poplar wood was investigated. For each solution, the sorption behaviour of veneer sapwood samples and the effect of sorption on wood
\end{abstract}

C2MA is member of the European Polysaccharide Network of Excellence (EPNOE), http://www. epnoe.eu.

J. Bossu

juliebossu@hotmail.fr

N. Le Moigne

nicolas.le-moigne@mines-ales.fr

S. Corn

stephane.corn@mines-ales.fr

P. Trens

philippe.trens@enscm.fr

F. Di Renzo

francesco.di-renzo@enscm.fr

1 Institut Charles Gerhardt Montpellier - UMR 5253 CNRS, Université de Montpellier-ENSCM, 240 Avenue Emile Jeanbrau, 34296 Montpellier Cedex 5, France

2 Centre des Matériaux des Mines d'Alès (C2MA), IMT Mines Alès, Université de Montpellier, 6 Avenue de Clavières, 30319 Alès Cedex, France 
viscoelasticity and microstructure were measured through vapour sorption gravimetry, dynamic mechanical analysis and optical microscopy monitoring. Pure water and pure ethanol showed contrasting sorption behaviour, ethanol leading to a much lower swelling and a very limited softening compared to water, despite comparable sorbed amounts. This result suggests different affinities of water and ethanol for biopolymers within wood microstructure. With mixed solutions, larger swelling and stronger variations in viscoelastic behaviour than in pure solvents were observed, confirming the synergistic effect of water/ethanol mixtures on structure and properties of wood cells. Microscopic observations evidenced that ethanol, both alone and in aqueous solutions, generates intercellular decohesion and disbonding of the different wood cell wall layers. These observations are consistent with a mechanism of partial solubilization by ethanol of lignin-related phenolic. This could lead to a release of the constraints which limit the swelling of the polysaccharide fraction of the cell wall by water. Such phenomenon is likely to be at the origin of the hyperswelling observed in mixed water/organic solvent systems.

\section{Introduction}

As an answer to the increasing demand in biomaterials for packaging, furniture industry and construction, wood and wood-based products could stand as competitive solutions. Indeed, the excellent physical and mechanical properties of wood fibres, the accessibility of the resources and the possible conversion into biocomposites are strong arguments making wood an attractive source of materials. Nonetheless, because of its hygroscopic nature, wood is subject to swelling in contact with liquids. This phenomenon needs to be better understood and controlled to promote the use of wood in technical applications.

Depending on the nature of the adsorbed liquid, the extent of swelling has been reported to be highly variable (Gordy 1941). Similar effects were also observed in the swelling of lignocellulosic materials and cellulose (Prusov et al. 2014), as well as for wood-polymer composites (Zhang et al. 2006). The correlation between the characteristics of the liquids and their effect on swelling has been mainly discussed in terms of molecular size and polarity. Several authors described a negative correlation between molar mass and swelling rate, due to the greater difficulty for larger molecules to diffuse into the fine structure of wood cell wall (Ishimaru and Maruta 1996; Ishimaru and Sakai 1988; Stamm and Loughborough 1942; Stamm and Tarkow 1950). Nayer (1948) and Nayer and Hossfeld (1949) also reported higher swelling in polar liquids characterized by high bonding capacity, which is explained by the greater and faster penetration of the liquids into wood cell walls. These results are confirmed by Mantanis et al. (1994a, b, 1995), who tested a large variety of pure solvents and wood species and reported that both hydrogen bonding capacity and size of the solvent molecules contribute to the extent of wood swelling.

However, there are still unexplained results: dimethyl sulfoxide (DMSO), for example, swells wood twice as water does despite lower polarity and higher molecular mass compared to water. 
Wood swelling in pure solvents is well documented. Yet, in many industrial applications, organic solvents are often combined with water, already present in the wood. Studying the effect of aqueous solutions containing organic solvent on wood swelling has then a special technological relevance. The complexity of the phenomena involved, however, leads to surprising observations.

Robertson (1964) observed that binary mixtures of liquids can produce more swelling than either component alone and that this synergistic effect is particularly notable when water is one of the liquids. Later, O'Leary and Hodges (2001) mentioned that such systems behave "strangely" and reported that preferential adsorption of certain components within binary systems can cause disproportionate tangential swelling. In this study, the specific case of water-ethanol solutions, which are involved in a large range of industrial uses, is addressed. Studying poplar and pinewood in green and dry conditions, Chang et al. (2009, 2012) and Meier et al. (2005) reported that water-ethanol solutions generate "hyperswelling", namely a swelling more important than that observed for either pure water or pure ethanol. More precisely, the most important deformations were reported for a $50 \%$ volume fraction of ethanol. Similar results were observed on gels of acetylated lignin, showing no swelling in ethanol but eight times the initial volume for swelling in water/ ethanol 50\% (Nishida et al. 2003).

High swelling rate strongly influences wood mechanical properties. But, albeit the process of adsorption on wood and its effect on wood viscoelastic properties have been widely studied for water (Engelund et al. 2013; Wang et al. 1991) and several pure solvents (Ishimaru et al. 2001a; Ma et al. 1991), only a limited number of studies are available in the case of ethanol. In other lignocellulosic materials, it has been shown that aqueous solutions of ethanol can strongly affect the static mechanical properties. For example, alteration of both tensile and shear strength of bamboo fibres composites has been evidenced upon aqueous treatments with ethanol (Hu et al. 2016; Qin and Yu 2009). Regarding wood, Meier et al. (2006b) found that both static bending and compression strength of pinewood swollen in aqueous solutions of ethanol were decreased by about the same amount as when using pure water. To date, there is no comprehensive explanation of these experimental observations.

To investigate these questions, it was considered in this work that studying the effect of water-ethanol sorption on both mechanical properties and wood fibres microstructure was a promising avenue of research. Wood microstructure is characterized by a non-homogeneous supramolecular organization. The specific composition of the layered structure of wood cell walls could explain why the sorption of binary solvents results in non-homogeneous hygroscopic and mechanical behaviours. The use of aqueous solutions of ethanol might lead to selective extraction of some of the cell wall and middle lamellae components, accompanied by alterations in stress transfer mechanisms within cell walls and between wood cells. Such phenomenon would result in the modification of the physico-mechanical and hygroscopic properties of lignocellulosic fibres. This hypothesis is supported by the observations of Meier et al. (2005, 2006a, b), who reported that ethanol-water mixtures generate local decohesion of individual cells. Studies on other lignocellulosic materials also identified specific effects of the cooperative sorption of water and organics on the different layers 
of primary and secondary cell walls. Acera Fernández et al. (2016) showed that the removal of non-cellulosic components from the cell walls of flax fibres with various aqueous and organic solvents could strongly affect the transverse mechanical properties of the fibres and their composites. In aqueous solutions of DMSO, Le Moigne et al. (2008, 2010) and Le Moigne and Navard (2010) also observed gradients in swelling and dissolution between the different cell walls of lignocellulosic fibres.

To better understand the phenomenon of wood hyperswelling observed in aqueous solutions containing organic solvents, it is then proposed to use poplar wood and water-ethanol binary mixtures as a reference system to clarify the nature of the synergistic effect of these two solvents on wood samples. Investigating the specific contributions of water and ethanol to sorption, swelling and viscoelastic wood properties, it is aimed to improve the understanding of the swelling mechanisms of wood in mixed solvents. For this purpose, first the sorption behaviour of poplar wood veneers in water, ethanol and their binary mixtures was studied to observe the influence of ethanol concentration on sorption behaviour. Second, the effect of sorption on samples' dynamic mechanical properties was measured to see whether both solvents are sorbed in similar absorption sites, and assuming that different sorption sites could give rise to different changes in the dynamical mechanical behaviour. Finally, the impact of sorption on the deformation of cell walls and on the intercellular cohesion was evaluated by microscope monitoring, to characterize the effect of the different mixtures on wood microstructure.

\section{Materials and methods}

\section{Wood sampling and mixed solvents}

Poplar was chosen as a model wood material due to its regular microstructure and low extractive content, thus limiting the issues related to wood inherent variability. This species is also widely naturally spread and planted in Europe and North America and a future growth in poplar utilization is expected in the area of composite products, bioenergy and chemicals (Balatinecz et al. 2014). Unheated and untreated poplar veneers (Populus tremula) were cut with a hydraulic press in the same sapwood zone along the fibre direction (i.e. $R=5 \mathrm{~mm} \times T=0.5 \mathrm{~mm} \times L$ $=45 \mathrm{~mm})$ and stabilized for 2 months at room conditions $\left(25^{\circ} \mathrm{C} ; 45 \% \mathrm{RH}\right)$. The resulting samples were homogeneous and almost free from extractives, thus limiting the potential influence of s econdary metabolites on wood sorption (Bossu et al. 2016). Solvents used for adsorption experiments were outgassed deionised water and ethanol $(99.9 \%$, Aldrich). Three binary mixtures made of water and ethanol were prepared with different $\mathrm{m}$ ass $\mathrm{f}$ ractions e thanol/(ethanol $+\mathrm{w}$ ater) (0.21, 0.44 and 0.70). The calculated molar fractions of ethanol in the resulting mixed solvents (named 21\% EtOH, 44\% EtOH and 70\% EtOH) are 0.09, 0.24 and 0.48 . 


\section{Gravimetric sorption measurements}

Vapour sorption measurements were performed by dynamic vapour sorption (DVS), a technique largely used to determine sorptive properties of wood and biomaterials (Engelund et al. 2010; Hill et al. 2010; Lequin et al. 2010; Källbom et al. 2016; Ormondroyd et al. 2016; Hosseinpourpia et al. 2016, 2017). In the isotherm gravimetric sorption instrument (DVS-Vacuum, Surface Measurement Systems, London, UK), the vapour pressure is obtained from temperature control of liquid sorbates placed in reservoirs. A mass flow controller ensures a constant admission of vapour generated from the liquid sorbates into the nitrogen flow to the balance cell. High vacuum can be obtained in the balance using a membrane pump coupled to a molecular pump. A butterfly valve on the pump allows reaching a targeted absolute pressure in the balance under continuous gas flow. The vapour pressure is controlled through the ratio of gas flows from the vapour reservoir and the dry carrier nitrogen bottle. Successive steps of relative pressures $\left(\mathrm{p} / \mathrm{p}^{\circ}\right)$ were set for determining the whole sorption isotherm. The equilibrium criterion for each step of the sorption isotherms was set with a mass variation ratio $\mathrm{d} m / \mathrm{d} t$ of $0.005 \% / \mathrm{min}$. Each wood specimen was loaded and dried in situ at $40{ }^{\circ} \mathrm{C}$ under high vacuum $\left(2 \times 10^{-6}\right.$ Torr $)$ for $10 \mathrm{~h}$. Solvent sorption measurements were performed at $25^{\circ} \mathrm{C}$. The values of the saturation pressure of each component of the ethanol aqueous solutions are reported in Supplementary Materials 1. The typical duration of a sorption-desorption cycle was $30 \mathrm{~h}$. These conditions have been shown to be adequate for reaching constant mass uptake in each step of water vapour sorption for sample size used in these experiments (Bratasz et al. 2012; Wong 2017). The sorption isotherms were best fitted by the GAB model with GraphPad Prism 6 software. Water sorption measurements were also conducted on a powdered wood sample prepared by $2-\mu \mathrm{m}$ milling with a Retsch SM 100 cutting mill.

\section{Dynamic mechanical characterization by DMA}

Modified mechanisms of wood swelling can induce complex variations in the mechanical behaviour over time. In these cases, dynamical studies are more adapted to track transient mechanical changes occurring during sorption processes. For this reason, the effect of solvents sorption on the dynamic longitudinal mechanical behaviour of wood specimens were analysed by coupling a Dynamic Mechanical Analyser (DMA) (50N Metravib) with a tank connected to a thermostatic bath regulated at $40{ }^{\circ} \mathrm{C}$ (see Fig. 1). Samples were mounted in tensile mode and clamped between the jaws with a torque wrench at $2.5 \mathrm{~N} / \mathrm{m}$ before being immersed in the different solvents. First trials were conducted for assessing the linear viscoelastic domain of the specimens. The optimal amplitude of the dynamic displacement was found to be $5 \mu \mathrm{m}$.

The variations of the complex modulus $E^{*}$, which is composed of the storage modulus $E^{\prime}$ (real part) and loss modulus $E^{\prime \prime}$ (imaginary part), and the damping $\left(\tan \delta=E^{\prime \prime} / E^{\prime}\right)$ were measured at a frequency of $0.05 \mathrm{~Hz}$ all along the absorption process during $2 \mathrm{~h}$. Four repetitions were operated for water and ethanol and three 


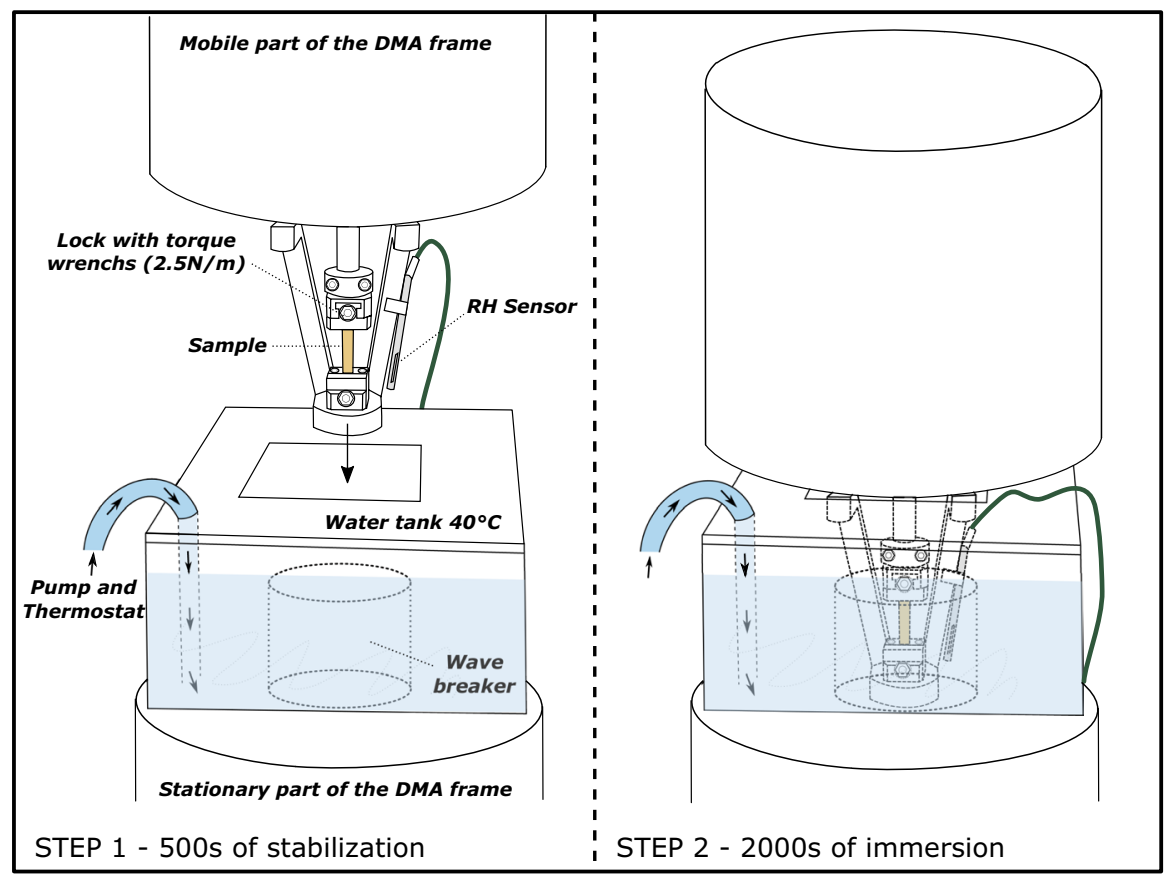

Fig. 1 Description of the protocol used for the dynamic mechanical characterization by DMA during the immersion of the poplar samples (here loaded in traction mode) into the tank of solvent connected to a thermostat bath maintained at $40{ }^{\circ} \mathrm{C}$

repetitions for mixed solvents. To enable comparison between the different tests, relative $E^{\prime}$ and relative $\tan \delta$ were calculated, normalizing the current values by the initial values of $E_{0}^{\prime}$ and $\tan \delta_{0}$ measured after $500 \mathrm{~s}$ of stabilization and just before $t_{0}$ corresponding to the beginning of immersion. Dynamic mechanical behaviour in shear mode was also investigated using the same protocol.

The exact compositions of the solutions were checked before and after each measurement using gas chromatography-mass spectrometry (GC-MS). No modification of the composition could be observed during the experiments that would originate from selective evaporation, thus indicating a good sealing of the apparatus.

\section{Optical microscopy observations}

After mechanical testing, each sample was equilibrated with each solution before being cut into thin radial slices of $25 \mu \mathrm{m}$ thickness with a WSL GSL1 sledge microtome in three different zones. The slices were then placed between two glass plates with the same solution to monitor the thickness and microstructure of the cell walls with a Leica DM LM/P optical microscope in transmission mode. In each slice, the average wall thickness of the cells was obtained by measuring the thickness of each visible cell on ten points and averaging the results. 


\section{Results and discussion}

\section{Sorption of vapours}

\section{Pure solvents}

The sorption isotherms of water at $25^{\circ} \mathrm{C}$ on poplar powder and solid specimens are shown in Fig. 2. Both sorption isotherms could be classified as type II, according to the IUPAC, which is characteristic for non-porous materials. The water uptake at saturation $\left(17\right.$ or $19 \% \mathrm{w} / \mathrm{w}$ at $\left.\mathrm{p} / \mathrm{p}^{\circ}=0.95\right)$ as well as the steep slope at low relative pressure $\left(\mathrm{p} / \mathrm{p}^{\circ}<0.1\right)$ are consistent with former studies on similar materials (Peralta 1995). Sorption isotherms on biomass-based materials are frequently modelled by the GAB (Guggenheim, Anderson, de Boer) method, which has been developed to extend the isotherm modelling of the BET (Brunauer, Emmet, Teller) method (Brunauer et al. 1938) by considering the adsorption energy level not just of surface monolayers but also of interacting multilayers (Anderson 1946). The GAB equation is formally equivalent to other extensions of the BET theory (Dent 1977) but also to models based on a different approach (Hailwood and Horrobin 1946; Okoh and Skaar 1980). The Hailwood and Horrobin model was developed to account for water uptake by polymer gels and attributes the strongest sorption to absorbed "hydration" water molecules in direct interaction with the polymer and a weaker sorption to "dissolved" water contributing to the gel swelling. The formal equivalence of the models indicates that, based on uptake isotherms alone, it is impossible to differentiate between surface adsorption and bulk absorption phenomena (Prothon and Ahrné 2004). In the case of food samples, it was early realized that the sorption of vapours penetrating inside a low-surface area material could also be modelled by the GAB method, which allowed to evaluate the sorption of "bound" and "free" sorbate instead of, respectively, monolayer and multilayer adsorption (Quirijns et al. 2005). In the case of wood samples, this interpretation is strongly supported by the

Fig. 2 Isotherms of sorption of ethanol vapour on poplar veneers (red), water vapour on poplar veneers (dark blue) and water vapour on poplar powder (light blue) at $25^{\circ} \mathrm{C}$. Adsorption (solid lines) and desorption (dashed lines)

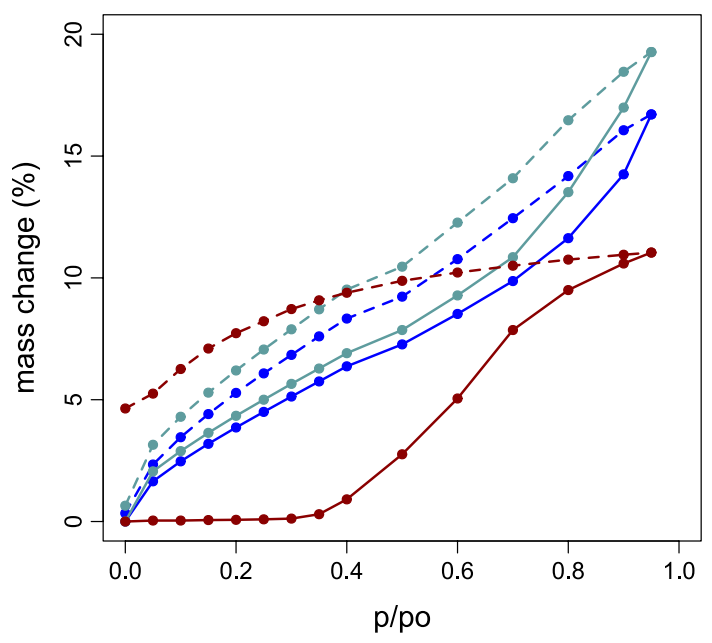


observation that typical GAB "monolayer" sorption values are two orders of magnitude larger than monolayer adsorption values measured by non-penetrating $\mathrm{N}_{2}$ (Bratasz et al. 2012; Clair et al. 2008).

In the GAB isotherm

$$
\frac{X}{X_{\mathrm{m}}}=\frac{C K \alpha}{(1-K \alpha) \cdot(1-K \alpha+C K \alpha)}
$$

$X$ is the mass uptake at $\mathrm{p} / \mathrm{p}^{\circ}=\alpha, X_{\mathrm{m}}$ is the mass uptake at the conventionally called "monolayer" value and can be attributed to "bound" sorbate. $C$ is an energetic constant related to the ratio of the Gibbs free energies of "bound" and "free" sorbate, and $K$ is the ratio between the Gibbs free energy of the bulk liquid and the "free" sorbate. The values of the GAB constants for the different samples are reported in Table 1.

The values of the GAB parameters for water sorption on whole and powdered specimens of poplar veneer are alike, as expected by the similarity of the sorption isotherms. The $X_{\mathrm{m}}$ and $C$ values indicate that nearly $5 \% \mathrm{w} / \mathrm{w}$ of water is sorbed with high affinity for the material. The $K$ parameter is essentially of entropic nature and its value, lower than 1, suggests that water molecules sorbed beyond the "monolayer" are significantly more structured than in bulk liquid water. The similarity of the water sorption isotherms on whole specimens and powders indicates that (1) the external surface area and the size of the material have a very limited influence on the sorption of water vapour and that (2) diffusion in the specimens - at least at the scale of the current samples-is not a limiting factor.

The desorption branches are shifted to a lower relative pressure as compared to the sorption branch. Full reversibility is observed, as the desorption branches go back to the origin as the relative pressure tends to zero. A significant feature of the hysteresis loop is the lack of the sudden step-down of the desorption branch with convergence to the adsorption branch at a relative pressure defined by the nature of the sorbent and by temperature (Ravikovitch and Neimark 2002; Thommes et al. 2016). This phenomenon, typical of sorption in mesoporous materials, takes place at $\mathrm{p} / \mathrm{p}^{\circ}$ near 0.31 in the case of water at room temperature (Sing and Madeley 1954). This so-called catastrophic desorption occurs when capillary tension in small mesopores exceeds the tensile strength of the condensed liquid (Burgess et al. 1989; Trens et al. 2005). This phenomenon is systematically absent in vapour sorption cycles on wood (Bratasz et al. 2012; Hill et al. 2010; Källbom et al. 2016),

Table 1 GAB constants for the adsorption isotherms

\begin{tabular}{lrll}
\hline & $C$ & $K$ & $X_{\mathrm{m}}(\mathrm{mg} / \mathrm{g})$ \\
\hline Water on powder & 11.6 & 0.75 & 56 \\
Water & 10.2 & 0.72 & 54 \\
$21 \% \mathrm{EtOH}$ & 7.1 & 0.85 & 67 \\
$44 \% \mathrm{EtOH}$ & 7.4 & 1.07 & 55 \\
$70 \% \mathrm{EtOH}$ & 8.9 & 1.43 & 36 \\
\hline
\end{tabular}


indicating that the hysteresis loops cannot be attributed to a simple capillary condensation. The observed hysteresis is typical of an activated sorption process, compatible with a swelling mechanism in which the sorbate is absorbed within the bulk of the material.

The sorption isotherm obtained with pure ethanol has a type V sigmoidal shape (see Fig. 2). This type of isotherm is usually described as being the result of cooperative adsorption of species, in which a weak adsorption of isolated molecule is accelerated at the relative pressure corresponding to the formation of surface molecular clusters. However, at low relative pressure of ethanol, there is almost no adsorption $\left(0.1 \% \mathrm{w} / \mathrm{w}\right.$ up to $\left.\mathrm{p} / \mathrm{p}^{\circ}=0.3\right)$, whereas at saturation, the sorbed amount of ethanol is $11 \%(\mathrm{w} / \mathrm{w})$. Such an extremely sigmoidal shape of the curve cannot be accounted for by simple models of surface adsorption and cannot be modelled by BET, BJH or GAB methods. To grasp the scale of the phenomenon, it is useful to observe that the formation of a monolayer of ethanol (cross-sectional area nearly $0.17 \mathrm{~nm}^{2}$ ) on a poplar veneer with nitrogen surface area $0.5 \mathrm{~m}^{2} \mathrm{~g}^{-1}$ (Clair et al. 2008) would correspond to a limited mass uptake of just $0.02 \% \mathrm{w} / \mathrm{w}$. The ethanol sigmoidal sorption is outside the field of monolayer/multilayer surface adsorption. It really seems that a high chemical potential is needed to overcome a sorption energy barrier. If the uptake up to $\mathrm{p} / \mathrm{p}^{\circ} 0.3$ can reasonably be accounted for by surface adsorption, once the needed $\mathrm{p} / \mathrm{p}^{\circ}$ is reached ethanol penetrates inside the material. It is likely that the heterogeneity of the wood structure plays a role in the phenomenon, as experiment setting, pretreatment and wood species can do. Indeed, less strongly sigmoidal ethanol sorption isotherms have been obtained with very long equilibration times on vapour-treated birch and aspen (Chirkova et al. 2013).

Another major difference between water and ethanol sorption is the shape of the desorption branch. In the case of ethanol, a larger hysteresis can be seen, with a pronounced irreversibility. Indeed, $4.6 \% \mathrm{w} / \mathrm{w}$ of ethanol remains adsorbed on the substrate after desorption. This irreversibility, strongly suggestive of chemisorption, confirms that the sorption of ethanol occurs in the bulk of the material.

\section{Mixed solvents}

The sorption isotherms of water-ethanol mixed vapours can be compared with that obtained with the pure components (see Fig. 3) with just one caveat: it has to be kept in mind that, unlike the case of the pure vapours, the composition of the adsorbed phase on the material does not necessarily correspond to the ethanol/water ratio in the vapour, due to a different affinity of each component for the substrate and a possible selectivity of adsorption.

The shapes of the sorption isotherms of mixed vapours are reminiscent of that found for the sorption of water. However, the initial mass uptake is steeper than in the case of pure water, as highlighted by the lower partial pressure needed to absorb up to $5 \%$ w/w (see Fig. 4, left side). Indeed, the GAB $X_{\mathrm{m}}$ "monolayer" value for the $21 \%$ EtOH sorption (see Table 1) is higher than for pure water, suggesting that the presence of water triggers the co-sorption of ethanol, even at low vapour pressure. The GAB $C$ parameter for the mixed vapours is always lower than for pure water vapour, indicating a lower average affinity of the absorbate for the absorbent. Quite 
Fig. 3 Isotherms of mixed water-ethanol solvents adsorption on poplar veneers specimens at $25^{\circ} \mathrm{C}$. Vapours at equilibrium of solutions with increasing ethanol mass fraction. Isotherms of pure water and ethanol are represented in dotted lines for comparison
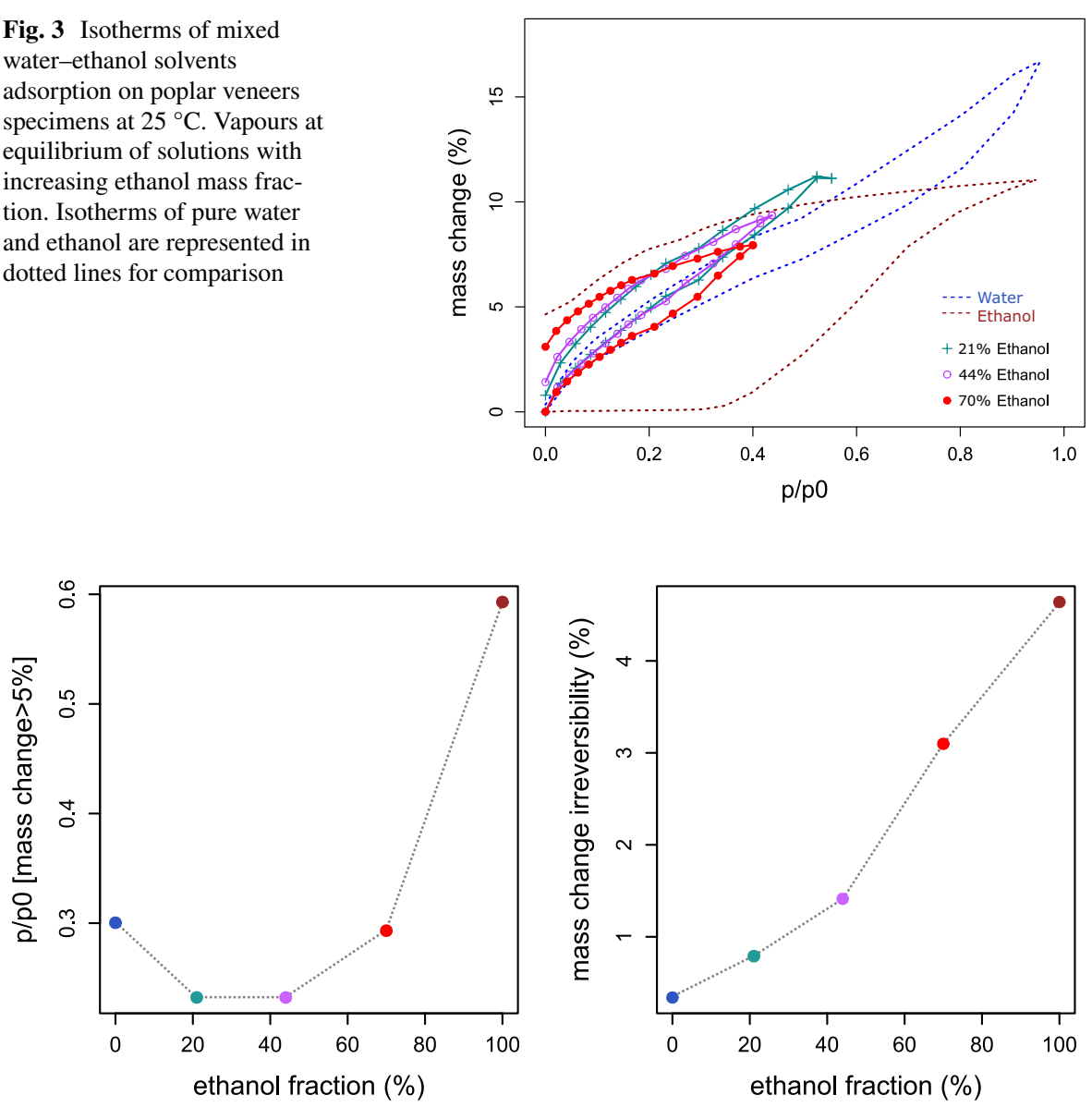

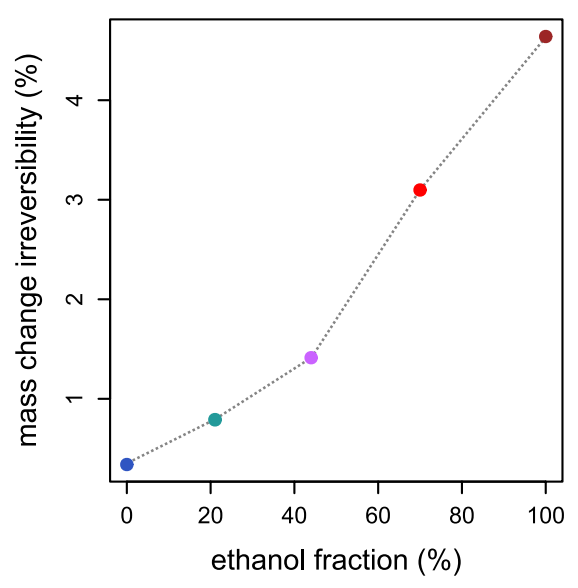

Fig. 4 Influence of ethanol fraction on the threshold partial pressure to reach $5 \%$ of mass change (left) and the irreversibility of mass change at $\mathrm{p}^{\circ}$ (right)

interestingly, the $K$ parameter increases with the ethanol fraction and reaches values higher than one, suggesting that the co-sorption of water and ethanol can lead to an absorbate phase more disordered than the corresponding bulk solvent. Globally, it can be deduced that the sorption of mixed vapours is a true co-sorption of water and ethanol and that the sorption of water wipes out the surface energy barrier for the sorption of ethanol.

On the other hand, the influence of ethanol in the sorption of the mixture can be seen in the hysteresis loop which is quite wide, especially for high ethanol contents. Irreversible retention upon desorption can also be observed, albeit to a smaller extent than for pure ethanol (see Fig. 4, right side). It seems likely that ethanol can strongly interact with some of the components present in wood specimens and the extent of residual mass uptake after desorption is more important as the ethanol molar fraction increases. 


\section{Influence of solvent sorption on viscoelastic behaviour}

\section{Pure solvents}

Results from dynamic mechanical testing during immersion reveal that ethanol sorption has a much lower effect on the viscoelastic properties of poplar veneers samples compared to water (see Fig. 5). For ethanol sorption, the loss of relative storage modulus (namely $\left.E^{\prime} / E_{0}\right)(-0.05$ on average) and increase in relative damping (namely $\left.\tan \delta / \tan \delta_{0}\right)(+0.68$ on average) occur quickly after immersion (extreme values reached at $t=219 \mathrm{~s}$ on average). At longer times, a slow recovery can be observed, i.e. slight variations from the extreme to the final values corresponding to +0.01 and -0.26 of relative $E^{\prime}$ and relative $\tan \delta$, respectively. It must be pointed out that the results for sorption of ethanol were highly reproducible.

The modification of the initial sample viscoelastic properties is clearly more pronounced for water sorption. Regarding storage modulus, the final loss of relative $E^{\prime}$ is -0.35 , which is 9 times larger than observed for ethanol. Nonetheless, comparing the average variations of $E^{\prime}$ due to water or ethanol sorption, it can be noticed that the two curves have comparable shapes, even if the intensity of the phenomenon is more pronounced for water. Regarding damping, water sorption also entails much larger modification of relative $\tan \delta$ (increase of +2.21 on average, i.e. more than 5 times higher than ethanol), highlighting that the absorption of water within poplar wood cells induces a pronounced change in their viscoelastic properties. Indeed, an increase in damping is characteristic of an increase in the viscous contribution $\left(E^{\prime \prime}\right)$ to the complex modulus $\left(E^{*}\right)$. It indicates a higher molecular mobility and a loss of intermolecular interactions between the biopolymers constituting cell walls and middle lamella. Besides, the effects of water and ethanol sorption on $\tan \delta$ variations also differ in nature.

Wood-water interactions and its influence on dynamical mechanical properties are already well documented (Ebrahimzadeh and Bertilsson 1998). The final modifications of $E^{\prime}$ and $\tan \delta$ after impregnation with water are comparable to the results obtained by Ishimaru et al. (2001b) and Obataya et al. (1998). For ethanol, as no
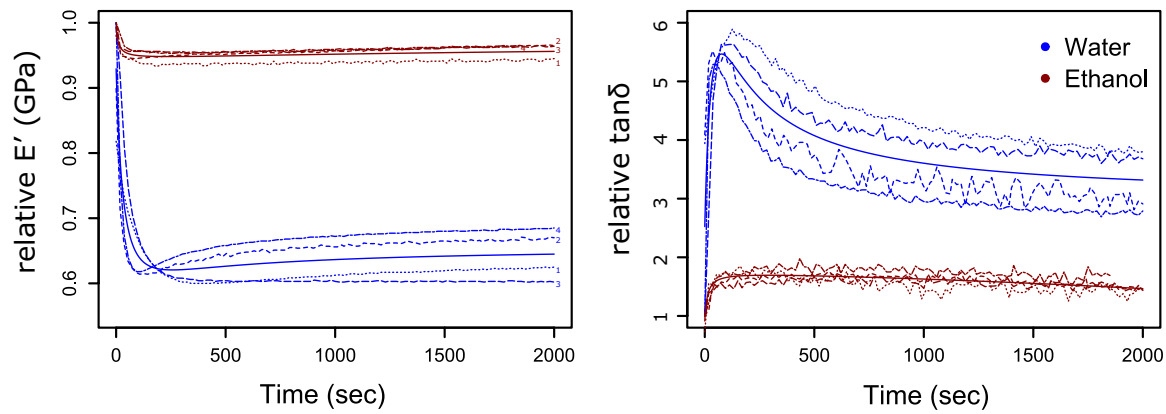

Fig. 5 Evolution of viscoelastic properties of poplar veneers specimens immersed in pure water and pure ethanol at $40{ }^{\circ} \mathrm{C}$. Relative storage modulus $E^{\prime}\left(E^{\prime} / E_{0}\right.$, left) and relative damping $\tan \delta\left(\tan \delta / \tan \delta_{0}\right.$, right) over time, after immersion at $t_{0}$ 
similar study has been conducted to the authors' knowledge, the influence of sorption on $E^{\prime}$ and $\tan \delta$ stands as a new result. Meier et al. (2006b) found that sorption of ethanol entails lower modifications of the static mechanical properties than water (two times lower compared to water), albeit this result was obtained for different loading modes.

The effect of variable humidity on $E^{\prime}$ and $\tan \delta$ after equilibrium has been widely studied in the case of water. Yet, regarding the immediate modification of the mechanical properties due to a sudden change of humidity, as performed in this study, there are fewer studies in the literature that can stand as a comparative reference. Here, it can be observed that water gives rise to a pronounced transitory state $(d \tan \delta \max =+4.61)$, i.e. seven times more than ethanol, followed by a large recovery (average decrease of -2.40 from the extreme to the final values). Numerous studies have shown that transient moisture conditions have additional effects on the mechanical properties of hygroscopic materials (Armstrong and Christensen 1961; Wang et al. 1991). These phenomena have been discussed in terms of instability originated by continual making and breaking of hydrogen bonds due to changes in moisture uptake in the path towards equilibrium (Gibson 1965; Nordon 1962). The slip zone model proposed by Hoffmeyer and Davidson (1989) illustrates this hypothesis. Through the identification by microscopy of zones of minute failures as distinct planes extending through the S2 layer of the cell wall, they showed that the changes of the elastic, viscoelastic, and plastic properties of wood are proportional to the number of slip planes, which increases with increasing moisture change. Later, Navi et al. (2002) showed that the transient hydrogen bonding between crystalline cellulose and the surrounding amorphous polymers, owed to the introduction or removal of water, may accelerate shear slip between the two phases in the presence of an external load. The recovery of $E^{\prime}$ observed here is then likely the consequence of rebonding of the fibrils after sorption. However, though the breaking and remaking of hydrogen bonds during transient moisture conditions may provide a general explanation of these transient phenomena, it does not provide a detailed explanation for the quantitative differences observed between water and ethanol. Moreover, there is little information about the potential mechanism played by ethanol.

Based on the present results and literature data, it is assumed that the strong variations in viscoelastic behaviour observed for water absorption are the result of the diffusion of water molecules within the secondary S2 cell wall layer, i.e. the main body of cell walls, at the origin of stiffness and longitudinal strength of wood (Bergander and Salmén 2002). Water molecules interact through H-bonding with hydrophilic biopolymers such as hemicelluloses located between more hydrophobic microfibrillar lattices, repulsing them one from another and giving rise to a pronounced macroscopic swelling of the specimens (Barbetta et al. 2017).

It was evidenced that ethanol molecules, like water molecules, are also absorbed by the material. Yet, the low resulting variations of $E^{\prime}$ and $\tan \delta$ indicate that the interactions of ethanol with wood biopolymers do not play a key role in the longitudinal mechanical properties of the fibres. This could be due to the nature of the interactions or to the location of the sorption sites. The large difference between mechanical properties after immersion in water or ethanol contrasts with the reasonably similar amounts of water and ethanol absorbed at saturation in the gravimetric 
adsorption experiments. If ethanol molecules were absorbed within cell wall layers at the same absorption sites as water molecules, their larger steric hindrance would generate more swelling and higher modifications in viscoelastic behaviour than water sorption, contrary to observed evidence. On these bases, it is assumed that the absorption sites of water and ethanol and the nature of their interactions with wood biopolymers are different and do not play the same role in the resulting viscoelastic behaviour of poplar wood.

\section{Mixed solvents}

In Fig. 6, the average results obtained upon immersion of poplar wood in pure and mixed solvents are compared. The variations of relative $E^{\prime}$ and $\tan \delta$ after immersion in water-ethanol mixtures show a trend which is similar to the one observed for water at short immersion times: an initial transitory state, particularly evident in damping. At
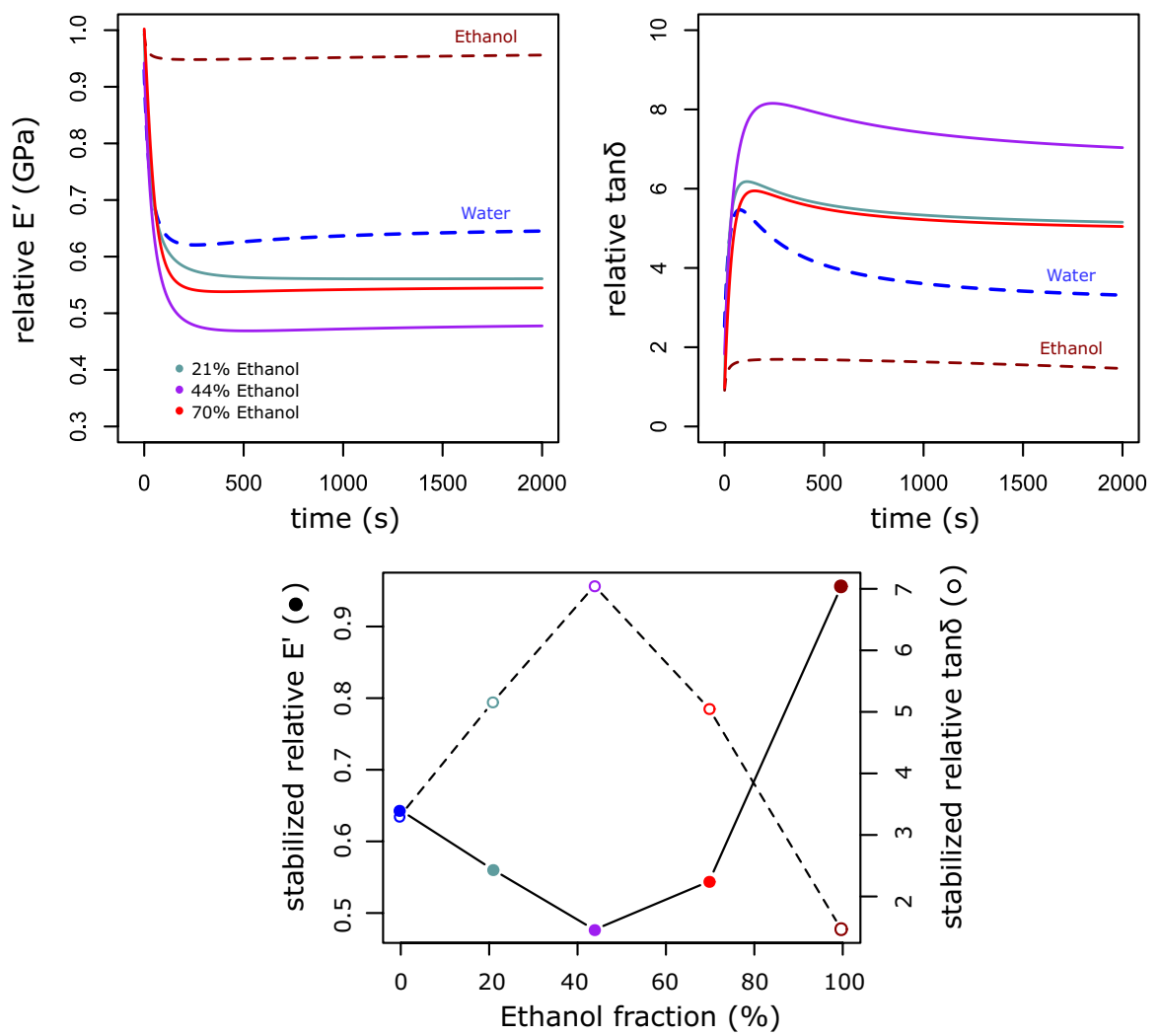

Fig. 6 Comparison of the effect of sorption of pure ethanol and water (dashed lines) and mixed solvents of different concentrations (solid lines) on viscoelastic behaviour of poplar veneers specimens. Relative $E^{\prime}$ (top left) and relative $\tan \delta$ (top right) over time after immersion at $t_{0}$. Influence of ethanol fraction on stabilized values of relative $E^{\prime}$ and $\tan \delta$ (bottom) 
longer immersion times, the recovery of viscoelastic properties is slower and weaker than in the case of water. The average final modifications of relative $E^{\prime}$ after immersion in $21 \% \mathrm{EtOH}, 44 \% \mathrm{EtOH}$ and $70 \% \mathrm{EtOH}$ ethanol-water solutions are -0.44 , -0.52 and -0.45 , respectively. Regarding relative $\tan \delta$, the same solvents induced an increase of $+4.15,+6.04$ and +4.05 , respectively (see Supplementary Materials 2 for details of each test). The decrease in relative $E^{\prime}$ and increase in relative $\tan \delta$ in mixed solvents are always higher than those observed with pure water. This result indicates that ethanol-water mixtures have a specific synergistic contribution to wood swelling and variation in viscoelastic behaviour. The maximal variations are observed with $44 \%$ $\mathrm{EtOH}$, where relative $E^{\prime}$ and relative $\tan \delta$ reach extreme values of -0.53 and +7.15 , respectively, i.e. 1.5 times more than for pure water. Variations in viscoelastic properties after sorption show a parabolic evolution as a function of the ethanol concentration (see Fig. 6), highlighting again the synergistic effect of mixed solvents.

The sluggish evolution of mechanical properties after their maximum variation is evidenced by several effects. In the curves of mechanical behaviour in Fig. 6, it can be remarked that $\tan \delta$ reaches maximal values in a shorter time in pure water than in mixed solvents. In mixed solvents, the time to reach extreme values is maximal in $44 \% \mathrm{EtOH}$. Water sorption is also characterized by a larger recovery of relative $\tan \delta$ (roughly -0.40), significantly higher than the value observed for mixed solvents (roughly -0.17 ) or for pure ethanol. This gradual decrease in relative $\tan \delta$, after reaching extreme variations corresponds to a local rearrangement of sorbate molecules that occurs within the cell walls structure after swelling. As shown above, the sorption of water alone is fully reversible, while ethanol sorption is partially irreversible, which means that the sorbed water molecules can be easily extracted from the material. In the presence of ethanol, either alone or in aqueous solutions, the recovery of mechanical properties after reaching extreme values is more sluggish and limited. This effect could be related to the irreversible retention of ethanol observed in gravimetric sorption experiments. Quite likely, the presence of retained ethanol molecules slows down the entire sorption-desorption process and prevents a complete recovery after the transient state.

A possible mechanistic interpretation of these results could be that irreversibly adsorbed ethanol molecules damaged the pristine microstructure of wood cells and/ or intercellular cohesion. The effects of these phenomena could be evidenced by mechanical analysis during drying. It might be impossible to return to the initial mechanical properties, and the difference between initial and final mechanical properties might depend on ethanol molar fraction. However, irreversible changes such as hornification could also occur, making it difficult to discriminate the effects of individual sorbed molecules on the viscoelastic behaviour of wood samples.

\section{Optical microscopy observations}

\section{Pure solvents}

Slices of $25 \mu \mathrm{m}$ in thickness were sampled from specimens used for dynamic mechanical analysis in water, ethanol or mixed solvents, to be observed by optical 
microscopy. In Fig. 7, two microscopic slices tested in water and ethanol are shown, corresponding to the samples which displayed the most contrasting viscoelastic behaviour.

Regarding pure solvents, water and ethanol absorption result in two really contrasted effects on the cell wall layers. Wood cells from the samples immersed in water are tightly packed against each other and show thick secondary S2 layers. The different layers of the cell walls are compact and well bound to the middle lamella. On the contrary, in ethanol, secondary S2 layers swell to a lower extent and P wall seems less bound in middle lamella regions. Average wall thickness is nearly $3 \mu \mathrm{m}$ after swelling in water and $2 \mu \mathrm{m}$ after swelling in ethanol (see Fig. 9).

In addition, some peeling can be observed between the middle lamella and the cell walls after absorption of ethanol. The zoom on the sample tested with ethanol (see Fig. 7) enables a more precise definition of the damaged interface: the apparent separation seems to occur between the middle lamella and the primary wall (disbonding 1 in Fig. 7). These results are concordant with Meier et al. (2005) who observed a similar phenomenon on SEM images of pinewood swollen in ethanol. It also appears that ethanol absorption can entail the disbonding of the different layers of the secondary wall (disbonding 2 in Fig. 7), leading to the detachment of the internal part of the cell wall layers, which remain isolated in the lumen of the cells. This phenomenon can be the result of the weakening of the interface between S2 and S1 layers, as well as the detachment of the G-layer in the case of tension wood, as observed by Clair et al. (2005) on poplar specimens. It should also be pointed out that weakening of the intercellular cohesion due to ethanol absorption could have favoured the disbonding of wood cells during the cutting of the slices. In any case, ethanol absorption appears to be responsible for a weakening of the intercellular cohesion in poplar wood cell walls.

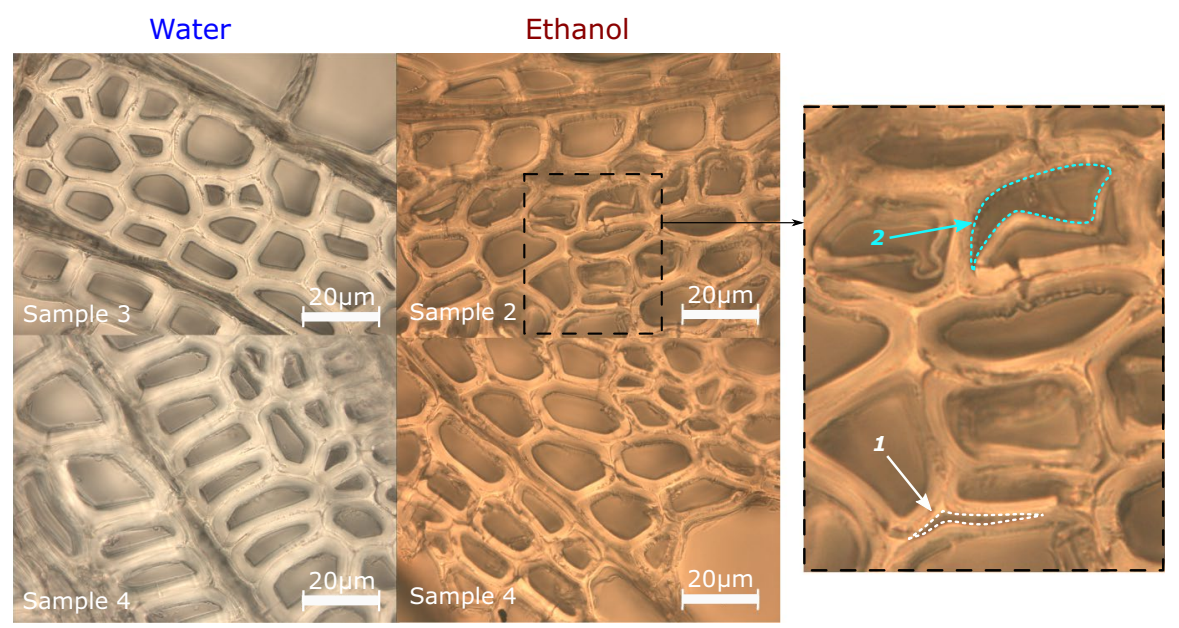

Fig. 7 Micrographs of the cell wall microstructure of poplar veneer specimens after absorption and dynamic mechanical analysis in the pure solvents $(\times 100)$. For each solvent, the two samples that displayed the most contrasting results during dynamical mechanical tests are presented 
Vapour sorption measurements have already shown that ethanol might preferentially react with lignin rather than cellulose (Lequin et al. 2013). Barrera-García et al. (2008) showed a different behaviour of wood components towards sorption of phenolics from hydro-alcoholic solutions. Apparently, cellulose and hemicellulose absorbed several phenolic compounds without apparent distinction, whereas lignin preferentially extracted some of these compounds from the hydro-alcoholic solution. The middle lamella, which is mainly composed of lignin and other phenolic compounds, might then preferentially interact with ethanol, being altered or even partially dissolved. This could explain the disbonding between primary wall and middle lamella. This hypothesis is also supported by the work of Hosseinpourpia et al. (2017), who observed that the removal of lignin on pinewood samples allows stronger swelling of the polysaccharide matrix. Within the secondary wall, S1 layer contains the greater amount of lignin, possibly explaining its disbonding from S2 wall. The weakening of the interface between S1 and S2 layers could allow the release of internal stresses originating from cell wall maturation. It is also likely that ethanol in aqueous solution leads to a better extraction of lignin. Indeed, in the field of papermaking, it has been shown that aqueous solutions of ethanol and acetone lead to higher lignin solubilization, with the highest efficiency obtained for volume concentrations around 50\% (Domínguez-Robles et al. 2018; Jääskeläinen et al. 2016).

The effect of ethanol sorption on the dynamic mechanical behaviour under shear was checked. It was assumed that the contribution of interfaces and intercellular cohesion to the mechanical properties of the samples would be more important in this loading mode (see Supplementary Materials 3). It was observed that the loss of E' modulus and increase of damping in ethanol was more pronounced in shear mode as compared to tensile mode, the relative variations of viscoelastic properties observed for ethanol and water absorption being similar. Even if ethanol can induce a pronounced intercellular decohesion and weaken the interfaces in wood microstructure, such results are not easy to interpret because of the superposition of different macromolecular and microstructural changes related to plasticization, hornification and decohesion. As pointed out above, this makes it difficult to discriminate the effects of individual sorbed molecules on wood samples.

\section{Mixed solvents}

In water-ethanol mixtures, a combination of high swelling due to water and intercellular decohesion due to ethanol can be observed (see Fig. 8). The micrographs of the wood cells from the samples immersed in $21 \% \mathrm{EtOH}$ are similar to those observed for water, but cells' external shapes present more rounded profiles on average. Cells are mostly packed together and only little disbonding between the middle lamella and the primary wall can be observed. For the samples immersed in $44 \% \mathrm{EtOH}$, both high swelling of the secondary S2 layer and frequent local disbonding between the middle lamella and the primary wall can be noticed. The average thickness of cell walls (see Fig. 9) reaches a maximum of $3.6 \mu \mathrm{m}$ for the $44 \% \mathrm{EtOH}$ sample. The coupling of water sorption and disbonding by ethanol appears to be the best combination to maximize microscopic swelling of wood cells. Indeed, in this situation, cells 


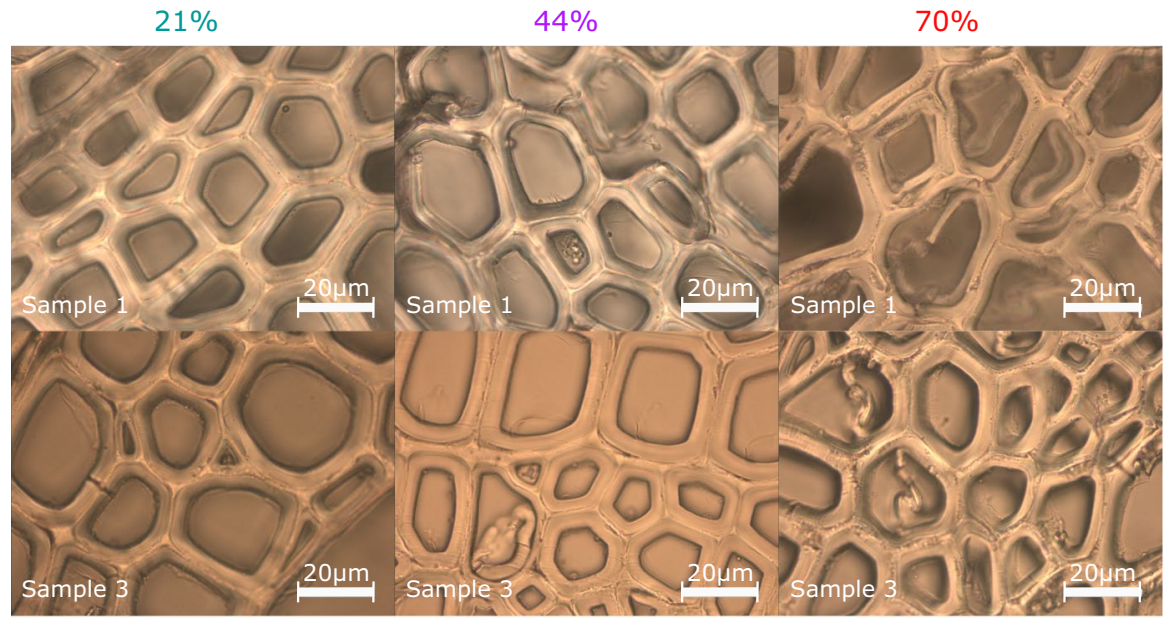

Fig. 8 Micrographs of the cell wall microstructure of poplar veneer specimens after immersion and dynamic mechanical testing in the different mixed solvents $(\times 100)$. For each solvent, the two tests of four that displayed the most contrasted viscoelastic behaviour are represented, to explore variability. Each test number is reported in the corresponding image

are less mutually constrained and the secondary S2 layer swells more freely. Finally, after immersion in $70 \% \mathrm{EtOH}$, the micrographs show cells that are almost all dissociated from the middle lamella with a slight swelling of S2 wall. In this specific case, it can be inferred that even if cell disbonding induced by ethanol favours the free swelling of S2 wall, there is no sufficient water uptake to swell it significantly. If ethanol reacts preferentially in lignin-rich regions as the middle lamella and the outer parts of the cell wall, it is also likely that pre-swelling of the inner S3 layer by water enables ethanol to get access to these sites. This hypothesis is supported by

Fig. 9 Influence of ethanol fraction on the final tangential free swelling of poplar microscopic cuts. Slices are immersed by capillarity in the solvents at $40{ }^{\circ} \mathrm{C}$ and dimensions are measured before and after swelling

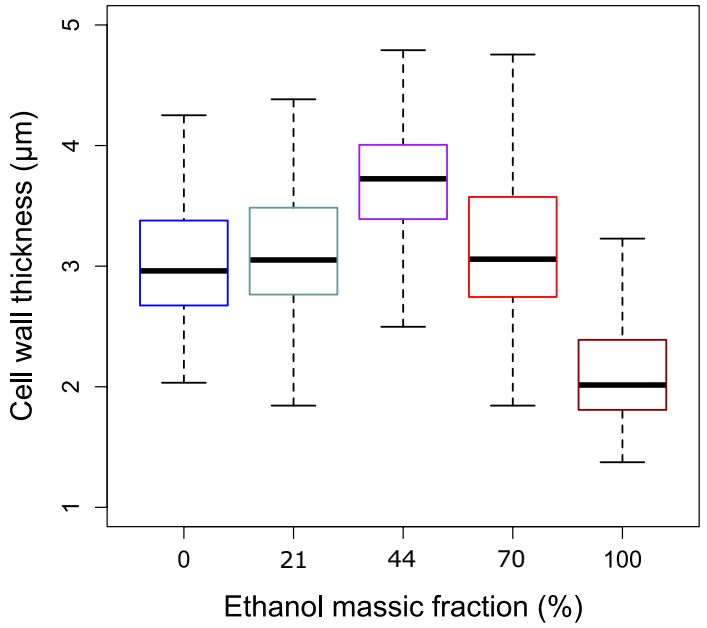


previous studies reporting that the extraction of polyphenols from plant materials is more effective with an ethanol concentration of approximately 70\% (Yang and Zhang 2008).

Additionally, post-mortem optical microscopy observations evidence that ethanol and water molecules act synergistically to separate and swell the cell walls, resulting in turn in the observed large decrease of the elastic modulus and large increase of damping in poplar wood specimens.

\section{Conclusion}

This study aimed to investigate the effect of the impregnation of aqueous solutions of ethanol of variable composition on the physico-mechanical properties of veneer poplar wood, to better characterize the phenomenon of hyperswelling generated by mixed solvents. Vapour sorption gravimetry, dynamic mechanical analysis and microscopic observations were combined to evaluate the modifications of microstructure and properties of wood induced by the interactions between water-ethanol binary solutions and wood constitutive biopolymers.

These techniques allowed comparing the sorption behaviour of wood in pure ethanol with the known and confirmed sorption behaviour in water. In both cases, the solvent uptake was several orders of magnitude larger than the amount corresponding to a monolayer-multilayer adsorption at the surface of poplar wood and evidenced absorption in the core of the material. Albeit the amount of water or ethanol absorbed at saturation differed by less than a factor of two, the two different solvents had drastically different effects on the properties of wood. The sorption of water brought about an important swelling of the cell walls and a fast plasticization of the material, characterized by high loss of longitudinal stiffness and increased damping. Upon sorption of ethanol, the longitudinal stiffness of wood samples was almost unchanged, and the average thickness of the cell walls was slightly increased. Moreover, the sorption of ethanol caused disbonding and structural damage in the more lignin-rich layers, i.e. middle lamella. This effect must be correlated with a significant retention of ethanol upon desorption, strongly suggestive of chemisorption of ethanol in the polyphenolic fraction. Interestingly, the damage around the middle lamellae did not significantly affect longitudinal mechanical properties but the induced loss of cohesion between cells corresponded to a significant loss of mechanical properties in shear loading mode. The measurements of sorption from vapours usefully completed the experiments by immersion evidencing that ethanol is virtually not absorbed at low partial pressure, suggesting the presence of selective diffusional barriers between the components of cell walls.

The simultaneous sorption of water and ethanol highlighted synergistic effects. Hyperswelling was indeed observed, as immersion in ethanol aqueous solutions induced larger swelling and larger softening than immersion in pure water or pure ethanol. Sorption from mixed vapours showed that the presence of water molecules allows ethanol to be absorbed also at low partial pressure, strongly suggesting that lignin-rich regions are more easily accessible to ethanol through hydrated holocellulosic fractions. When co-absorbed with water, ethanol generates cell 
decohesion, and it seems likely that the release of constraints between the wood cell wall layers plays an important role in enabling hyperswelling of cell walls when mixed solvents are absorbed.

These results suggest several orientations for future research programmes. The selective interactions of solvent components with different wood biopolymers are worth to be investigated and validated by molecular dynamic simulations. The synergistic swelling mechanism by mixed solvents, implying a loss of stiffness by selective alteration of lignin-rich structures, suggests useful developments of theoretical physico-chemical models of wood swelling (Barbetta et al. 2017). The mechanical study of the transitory states, a factor not to be underestimated in the evaluation of structural materials, represents a largely unexplored field when mixed solvents are concerned. It remains an open question to which extent the size of the specimens and diffusion mechanisms can affect the mechanical behaviour. As a last observation, the understanding of the mechanism of hyperswelling in mixed solvents other than water and ethanol remains terra incognita despite its technological relevance in industrial wood treatments and its service-life.

Acknowledgements We acknowledge funding from the Agence Nationale de la Recherche program Investissements d'Avenir in the framework of the contract ANR-10-LABX-05-01 (LabExCheMISyst). Poplar veneers were graciously provided by Maurice Orly, Danzer Company. The authors acknowledge the support of Surface Management Systems London and their team for DVS analyses, the technical support of Marc Longerey, Centre des Matériaux des Mines d'Alès (C2MA), for dynamic mechanical measurements, and the assistance of Olivier Arnoult, Laboratoire de Mécanique et Génie Civil (LMGC) of the Université de Montpellier, in microscopy techniques. The authors have especially appreciated the useful discussions with Thomas Zemb, Institut de Chimie Séparative de Marcoule (ICSM).

\section{References}

Acera Fernández J et al (2016) Role of flax cell wall components on the microstructure and transverse mechanical behaviour of flax fabrics reinforced epoxy biocomposites. Ind Crops Prod 85:93108. https://doi.org/10.1016/j.indcrop.2016.02.047

Anderson RB (1946) Modifications of the Brunauer, Emmett and Teller equation. J Am Chem Soc 68:686-691

Armstrong LD, Christensen GN (1961) Influence of moisture changes on deformation of wood under stress. Nature 191:869-870

Balatinecz J, Mertens P, De Boever L, Yukun H, Jin J, Van Acker J (2014) Properties, processing and utilization. In: Isebrands JG, Richardson J (eds) Poplars and Willows: Trees for Society and the Environment. CABI, Wallingford, pp 527-562. ISBN 978-1-78064-108-9

Barbetta A, Fratzl P, Zemb T, Bertinetti L (2017) Impregnation and swelling of wood with salts: ion specific kinetics and thermodynamics effects. Adv Mater Interfaces 4:1600437. https://doi. org/10.1002/admi.201600437

Barrera-García VD, Gougeon RD, Karbowiak T, Voilley A, Chassagne D (2008) Role of wood macromolecules on selective sorption of phenolic compounds by wood. J Agric Food Chem 56:84988506. https://doi.org/10.1021/jf801314n

Bergander A, Salmén L (2002) Cell wall properties and their effects on the mechanical properties of fibers. J Mater Sci 37:151-156. https://doi.org/10.1023/A:1013115925679

Bossu J, Beauchêne J, Estevez Y, Duplais C, Clair B (2016) New insights on wood dimensional stability influenced by secondary metabolites: the case of a fast-growing tropical species Bagassa guianensis Aubl. PLoS ONE 11:e0150777. https://doi.org/10.1371/journal.pone.0150777 
Bratasz Ł, Kozłowska A, Kozłowski R (2012) Analysis of water adsorption by wood using the Guggenheim-Anderson-de Boer equation. Eur J Wood Prod 70:445-451. https://doi.org/10.1007/ s00107-011-0571-x

Brunauer S, Emmett PH, Teller E (1938) Adsorption of gases in multimolecular layers. J Am Chem Soc 60:309-319

Burgess CGV, Everett DH, Nuttall S (1989) Adsorption hysteresis in porous materials. Pure Appl Chem 61:1845-1852

Chang SS, Clair B, Gril J, Yamamoto H, Quignard F (2009) Deformation induced by ethanol substitution in normal and tension wood of chestnut (Castanea sativa Mill.) and simarouba (Simarouba amara Aubl.). Wood Sci Technol 43:703. https://doi.org/10.1007/s00226-009-0251-8

Chang S, Quignard F, Di Renzo F, Clair B (2012) Solvent polarity and internal stresses control the swelling behaviour of green wood during dehydration in organic solution. BioResources 7:2418-2430

Chirkova J, Andersone I, Grinins J, Andersons B (2013) Sorption properties of hydrothermally modified wood and data evaluation based on the concept of Hansen solubility parameter (HSP). Holzforschung 67:595. https://doi.org/10.1515/hf-2012-0186

Clair B, Thibaut B, Sugiyama J (2005) On the detachment of the gelatinous layer in tension wood fiber. J Wood Sci 51:218-221. https://doi.org/10.1007/s10086-004-0648-9

Clair B, Gril J, Di Renzo F, Yamamoto H, Quignard F (2008) Characterization of a gel in the cell wall to elucidate the paradoxical shrinkage of tension wood. Biomacromolecules 9:494-498. https:// doi.org/10.1021/bm700987q

Dent RW (1977) A multilayer theory for gas sorption. Part I: sorption of a single gas. Text Res J 47:145-152

Domínguez-Robles J, Tamminen T, Liitiä T, Peresin MS, Rodríguez A, Jääskeläinen A-S (2018) Aqueous acetone fractionation of kraft, organosolv and soda lignins. Int $\mathrm{J}$ Biol Macromol 106:979-987

Ebrahimzadeh PR, Bertilsson H (1998) Effect of impregnation on mechanosorption in wood and paper studied by dynamic mechanical analysis. Wood Sci Technol 32:101-118. https://doi.org/10.1007/ BF00702591

Engelund ET, Klamer M, Venås TM (2010) Acquisition of sorption isotherms for modified woods by the use of dynamic vapour sorption instrumentation. Principles and practice. In: International research group on wood protection, vol IRG/WP 10-40518. The International Research Group on Wood Protection

Engelund ET, Thygesen LG, Svensson S, Hill CAS (2013) A critical discussion of the physics of woodwater interactions. Wood Sci Technol 47:141-161. https://doi.org/10.1007/s00226-012-0514-7

Gibson EJ (1965) Creep of wood: role of water and effect of a changing moisture content. Nature 206:213-215

Gordy WJ (1941) Spectroscopic comparison of the proton-attracting properties of liquids. J Phys Chem 9:204-215

Hailwood AJ, Horrobin S (1946) Adsorption of water by polymers: analysis in terms of a simple model. Trans Faraday Soc 42B:84-102

Hill CAS, Norton AJ, Newman G (2010) The water vapour sorption properties of Sitka spruce determined using a dynamic vapour sorption apparatus. Wood Sci Technol 44:497-514. https://doi. org/10.1007/s00226-010-0305-y

Hoffmeyer P, Davidson RW (1989) Mechano-sorptive creep mechanism of wood in compression and bending. Wood Sci Technol 23:215-227. https://doi.org/10.1007/BF00367735

Hosseinpourpia R, Adamopoulos S, Mai C (2016) Dynamic vapour sorption of wood and holocellulose modified with thermosetting resins. Wood Sci Technol 50:165-178. https://doi.org/10.1007/s0022 6-015-0765-1

Hosseinpourpia R, Adamopoulos S, Holstein N, Mai C (2017) Dynamic vapour sorption and waterrelated properties of thermally modified Scots pine (Pinus sylvestris L.) wood pre-treated with proton acid. Polym Degrad Stab 138:161-168. https://doi.org/10.1016/j.polymdegradstab.2017.03.009

Hu YA, He M, Zhu RX, Zhang YH, Yu YL, Yu WJ (2016) Influence of dyeing treatment on the performance of bamboo-based fibre composites. J Trop For Sci 28:112-120

Ishimaru Y, Maruta T (1996) Wood swelling and its transverse anisotropy in organic liquids having two or more functional groups in a molecule. Mokuzai Gakkaishi 42:234-242

Ishimaru Y, Sakai H (1988) Swelling of wood in liquid mixtures. Part I: water-ethanol and water-acetone. Mokuzai Gakkaishi 34:889-895 
Ishimaru Y, Narimoto S, Iida I (2001a) Mechanical properties of wood swollen in organic liquids with two or more functional groups for hydrogen bonding in a molecule. J Wood Sci 47:171. https://doi. org/10.1007/BF01171218

Ishimaru Y, Oshima K, Iida I (2001b) Changes in the mechanical properties of wood during a period of moisture conditioning. J Wood Sci 47:254-261. https://doi.org/10.1007/bf00766710

Jääskeläinen A-S, Liitiä T, Tamminen T (2016) Production of homogeneous kraft lignin by aqueous. In: European workshop on Lignocellulosics and Pulp, Autrans

Källbom S, Rautkari L, Wålinder M, Johansson L-S, Campbell JM, Segerholm K, Jones D, Laine K (2016) Water vapour sorption characteristics and surface chemical composition of thermally modified spruce (Picea abies karst). Int Wood Product J 7:116-123. https://doi.org/10.1080/20426 445.2016.1160590

Le Moigne N, Navard P (2010) Dissolution mechanisms of wood cellulose fibres in NaOH-water. Cellulose 17:31-45. https://doi.org/10.1007/s10570-009-9370-5

Le Moigne N, Montes E, Pannetier C, Höfte H, Navard P (2008) Gradient in dissolution capacity of successively deposited cell wall layers in cotton fibres. Macromol Symp 262:65-71. https://doi. org/10.1002/masy.200850207

Le Moigne N, Bikard J, Navard P (2010) Rotation and contraction of native and regenerated cellulose fibers upon swelling and dissolution: the role of morphological and stress unbalances. Cellulose 17:507-519. https://doi.org/10.1007/s10570-009-9395-9

Lequin S, Chassagne D, Karbowiak T, Gougeon R, Brachais L, Bellat J-P (2010) Adsorption equilibria of water vapor on cork. J Agric Food Chem 58:3438-3445. https://doi.org/10.1021/jf9039364

Lequin S, Chassagne D, Karbowiak T, Bellat J-P (2013) Sorption equilibria of ethanol on cork. J Agric Food Chem 61:5391-5396. https://doi.org/10.1021/jf4016043

Ma D, Johns WE, Dunker AK, Bayoumi AE (1991) The effect of donor-acceptor interactions on the mechanical properties of wood. In: Mittal K, Anderson h (eds) Acid-base interactions: relevance to adhesion science and technology. VSP, Utrecht, pp 343-361. ISBN 90-6764-135-9

Mantanis GI, Young RA, Rowell RM (1994a) Swelling of wood. Part I. Swelling in water. Wood Sci Technol 28:119-134. https://doi.org/10.1007/BF00192691

Mantanis GI, Young RA, Rowell RM (1994b) Swelling of wood. Part II. Swelling in organic liquids. Holzforschung 48:480. https://doi.org/10.1515/hfsg.1994.48.6.480

Mantanis GI, Young RA, Rowell RM (1995) Swelling of Wood. Part III. Effect of temperature and extractives on rate and maximum swelling. Holzforschung 49:239-248. https://doi.org/10.1515/ hfsg.1995.49.3.239

Meier P, Kaps T, Kallavus U (2005) Swelling of pinewood (pinus sylvestris) in binary aqueous solutions of organic substances. Mater Sci Medzg 11:140-145

Meier P, Kaps T, Kallavus U (2006a) Multiple swelling of pinewood (pinus sylvestris) in binary and ternary mixtures of ethanol, acetone and water. Mater Sci Medzg 12(1):25-30

Meier P, Stöör E, Kaps T, Kallavus U (2006b) Mechanical properties of pinewood (Pinus Sylvestris) swollen in organic liquids. Est J Eng 12:125-133

Navi P, Pittet V, Plummer CJG (2002) Transient moisture effects on wood creep. Wood Sci Technol 36:447-462. https://doi.org/10.1007/s00226-002-0157-1

Nayer AN (1948) Swelling of wood in various organic liquids. Ph.D. thesis. University of Minnesota, Minneapolis

Nayer AN, Hossfeld RL (1949) Hydrogen bonding and the swelling of wood in various organic liquids. J Am Chem Soc 71:2852-2855

Nishida M, Uraki Y, Sano Y (2003) Lignin gel with unique swelling property. Bioresour Technol 88:8183. https://doi.org/10.1016/s0960-8524(02)00264-x

Nordon P (1962) Some torsional properties of wool fibers. Text Res J 32:560-568

Obataya E, Norimoto M, Gril J (1998) The effects of adsorbed water on dynamic mechanical properties of wood. Polymer 39:3059-3064. https://doi.org/10.1016/S0032-3861(97)10040-4

Okoh KIA, Skaar C (1980) Moisture sorption isotherms of the wood and inner bark of ten southern U.S. hardwoods. Wood Fiber 12:98-111

O'Leary P, Hodges PA (2001) The relationship between full penetration uptake and swelling of different fluids. Wood Sci Technol 35:217-227. https://doi.org/10.1007/s002260100096

Ormondroyd GA, Källbom SK, Curling SF, Stefanowski BK, Segerholm BK, Wålinder MEP, Jones D (2016) Water sorption, surface structure and surface energy characteristics of wood composite fibres refined at different pressures. Wood Mater Sci Eng 12:203-210. https://doi.org/10.1080/17480 272.2016.1150343 
Peralta PN (1995) Sorption of moisture by wood within a limited range of relative humidities. Wood Fiber Sci 27:13-21

Prothon F, Ahrné LM (2004) Application of the Guggenheim, Anderson and De Boer model to correlate water activity and moisture content during osmotic dehydration of apples. J Food Eng 61:467-470. https://doi.org/10.1016/S0260-8774(03)00119-5

Prusov AN, Prusova SM, Zakharov AG (2014) Interaction of cellulose and lignocellulosic polymers with water and aqueous systems. Russ Chem Bull 63:1926-1945. https://doi.org/10.1007/s1117 2-014-0683-7

Qin L, Yu WJ (2009) Research on surface color, properties of thermo-treated reconstituted bamboo lumber after artificial weathering test. Adv Mater Res 79:1395-1398

Quirijns EJ, van Boxtel AJB, van Loon WKP, van Straten G (2005) Sorption isotherms, GAB parameters and isosteric heat of sorption. J Sci Food Agric 85:1805-1814. https://doi.org/10.1002/jsfa.2140

Ravikovitch PI, Neimark AV (2002) Experimental confirmation of different mechanisms of evaporation from ink-bottle type pores: equilibrium, pore blocking, and cavitation. Langmuir 18:9830-9837. https://doi.org/10.1021/la026140z

Robertson AA (1964) Cellulose-liquid interactions. Pulp Paper Mag Canada 65:171-178

Sing KSW, Madeley JD (1954) The surface properties of silica gels. II. Adsorption of water vapour. J Appl Chem 4:365-368

Stamm AJ, Loughborough WK (1942) Variation in shrinking and swelling of wood. Trans Am Soc Mech Eng 64:379-386

Stamm AJ, Tarkow H (1950) Penetration of cellulose fibers. J Phys Colloid Chem 54:745

Thommes M, Kaneko K, Neimark AV, Olivier JP, Rodriguez-Reinoso F, Rouquerol J, Sing KSW (2016) Physisorption of gases, with special reference to the evaluation of surface area and pore size distribution (IUPAC Technical Report). Pure Appl Chem 87:1051-1069. https://doi.org/10.1515/ pac-2014-1117

Trens P, Tanchoux N, Galarneau A, Brunel D, Fubini B, Garrone E, Fajula F, Di Renzo F (2005) A macrothermodynamic approach to the limit of reversible capillary condensation. Langmuir 21:85608564. https://doi.org/10.1021/la0507838

Wang JZ, Dillard DA, Kamke FA (1991) Transient moisture effects in materials. J Mater Sci 26:51135126. https://doi.org/10.1007/BF01143201

Wong HE (2017) Characterizing the kinetics of free and bound water using a non-isothermal sorption technique. Dry Technol 35:46-54. https://doi.org/10.1080/07373937.2016.1158722

Yang Y, Zhang F (2008) Ultrasound-assisted extraction of rutin and quercetin from Euonymus alatus (Thunb.) Sieb. Ultrason Sonochem 15(4):308-313. https://doi.org/10.1016/j.ultsonch.2007.05.001

Zhang Y, Zhang SY, Chui YH (2006) Water vapor adsorption and volumetric swelling of melt-impregnated wood-polymer composites. J Appl Polym Sci 102:2668-2676. https://doi.org/10.1002/ app. 24092 